\title{
Predictors of Employee Involvement in a Worksite Health Promotion Program
}

\author{
Kathryn Rost, PhD \\ Cathleen Connell, PhD \\ Kenneth Schechtman, PhD \\ Benico Barzilai, MD \\ Edwin B. Fisher, Jr., PhD
}

Although worksite health promotion programs have proliferated, little is known about the population they reach. This study of employees of a large utility company compared whether the same characteristics which predict recruitment also predict extended participation. The study also prospectively assessed how risk factors are related to employees' on-going extended participation. The findings demonstrate that sociodemographic predictors of recruitment are almost mirror images of the predictors of extended participation. Over time employees who are at higher risk for cardiovascular disease participated in on-going sessions less frequently. Data suggest that referral to targeted sessions does not result in higher rates of attendance by employees with a particular risk factor, although there is no evidence of selective avoidance. Organizational influences on participation evident from the beginning are sustained through four sessions. Programs targeting higher risk employees nested within worksite-wide programs may be useful to increase the extended participation of individuals at elevated risk for heart disease.

In addition to the ready cooperation of the employees who volunteered for the study, the authors of the paper would like to gratefully acknowledge the efforts of Wendy Jaffe, B.S.N. and Barbara Gaponoff, R.N., M.P.H. for the effort and care they devoted to intensive data collection. The work of Julie Heins and Cherie Hill in the preparation of the manuscript is also much appreciated. The grant was supported by the National Heart. Lung. and Blood Institute HL17646. Burton Sobel, M.D., principal investigator.

Kathryn Rost is the former Research Director, National Research and Demonstration Center Worksite Health Promotion Program; Kenneth Schechtman is Assistant Professor, Biostatistics; Benico Barzilai is Assistant Professor, Internal Medicine Principal Coinvestigator, National Research and Demonstration Center Worksite Health Promotion Program; and Edwin B. Fisher, Jr. is Associate Professor, Psychology Principal Coinvestigator, National Research and Demonstration Center Worksite Health Promotion Program at the Washington University School of Medicine, St. Louis, MO.

Cathleen Connell is Assistant Professor. Department of Health Behavior and Health Education School of Public Health University of Michigan.

Address reprint requests to Kathryn Rost, PhD, Department of Psychiatry and Behavioral Sciences, University of Arkansas for Medical Sciences, Slot 554, Little Rock, AR 72205 . 


\section{INTRODUCTION}

Although worksite health promotion programs that target multiple cardiovascular risk factors have been in existence for almost a decade, ${ }^{1.2}$ little is known about whether these programs are reaching the population most at risk for heart disease. The extent to which a program can involve higher risk employees, as well as the program's effectiveness in reducing those risk factors, ${ }^{3}$ will have an important influence on the prevalence of cardiovascular disease in a worksite population, and a potential long-term effect on health care costs. As important as it is to reach those individuals at risk, two of three major cardiovascular risk factors (hypertension and hypercholesterolemia) have been inconsistently related to recruitment, ${ }^{4-8}$ while the third (smoking) has been negatively related. ${ }^{4.5}$ Previous work suggests that psychosocial forces such as attitudinal ${ }^{1.4 .59 .10}$ and organizational factors ${ }^{8}$ may have more consistent influence on employee involvement.

One reason the literature to date provides limited understanding of factors which influence employee involvement in worksite programs which target multiple risk factors is that most studies have focused on whether or not employees complete an initial assessment or attend a single orientation session. This approach does not differentiate individuals who invest substantial amounts of personal energy in health promotion programs from those who come once and drop out. Similarly, such a focus does not allow one to determine whether higher risk individuals are attending those offerings which address their specific risk factor(s) in detail.

This article addresses this limitation in the literature by comparing whether the same characteristics which predict recruitment also predict extended participation, and by examining whether higher risk employees who are recruited to a program attend offerings which address their specific risk factor(s). In addition, the paper examines whether those employees with greater risk are more likely to become extensively involved in a worksite health promotion program over time than those employees at lower levels of risk.

\section{METHODOLOGY}

\section{Description of Research Setting}

This investigation emerged from Working Hearts, a five-year collaborative effort between the university and corporate sector to reduce known risks for heart disease in a worksite setting. The effort was aimed at all employees from 17 divisions at six geographic locations of a utility company. These divisions (averaging 77 employees) were invited into the study based on the following criteria: (1) they were sociodemographically representative of the company's entire work force; (2) management in each of the groups agreed to various program requirements, including allocation of "company time" for employee participation in various program components; (3) site visits by the research staff indicated employee interest; and (4) sufficient space at the worksite was available to conduct various program offerings. The program offered: (1) Screening for a variety of physical and behavioral risk factors for heart disease at no cost to 
the employee; (2) Individualized Counseling session with a nurse to review Screening results; (3) Weekly Presentations, a series of four sessions addressing risk factors and describing subsequent program offerings; and (4) various onsite workshops, activities, and intensive small group classes in weight and cholesterol reduction, smoking cessation, exercise, stress reduction, and blood pressure control over a 21-month period. Each division was enrolled sequentially (approximately one a month) into the program due to the intensive demand for staff time during the start-up phase of the project. This article reports on the employees in the first 13 divisions $(N=679)$ to enter the study.

\section{Recruitment}

Standard lines of communication within the company were utilized to recruit employees to the program and notify them of relevant details. A letter from the president of the company was sent to each employee announcing the initiation of the program and encouraging participation. A sign-up sheet was circulated among employees along with further written information describing what the program offered.

Completion of screening provided the recruitment data analyzed in this paper. In the screening phase of the program, employees were required to fill out a 24-page prepiloted questionnaire, and have their height, weight, and blood pressure recorded. All employees were encouraged to give a blood sample to determine cholesterol. The complete confidentiality of employee results was emphasized. Employees who did not go through screening initially were given a second opportunity at a later date. Everyone was informed that completing screening did not commit them to participating in any of the program's subsequent offerings.

In individual counseling sessions held approximately one month after screening, a project nurse identified those areas where employee risk was elevated (see Operational Definitions of Major Variables below) and encouraged employees to select areas to consider behavior change. The nurse provided each employee with a calendar of the four weekly presentations describing the sessions as an introduction to risk factors and risk factor change. While each employee was encouraged to attend all four sessions regardless of his or her personal risk profile, the nurse emphasized those sessions which addressed the employee's specific risk factor(s). Ninety-six percent of employees recruited to screening attended their individual counseling sessions with the nurse. The remaining group received their results by mail, along with the nurse's telephone number for further consultation.

In order to compare sociodemographic characteristics of employees recruited to the program with those employees who chose not to be recruited, a mail questionnaire was forwarded approximately three months after screening to each employee in two sites within the study. The two sites were selected such that: (1) one predominantly white and one blue collar site was included, (2) effort could be devoted to obtaining as close to a $100 \%$ response rate as possible, and (3) the number of employees who joined the program at each site was comparable to the average recruitment rate across sites. A second copy of the questionnaire 
and a self-addressed, stamped envelope was forwarded to each employee who did not return a questionnaire within two weeks after its distribution. Telephone prompts were used to encourage the remaining employees to return their questionnaires.

\section{Participation}

Attendance at the four weekly presentations provided the participation data for this article. Posters and memos were posted several days before each weekly presentation to remind employees of the time, place, and title of each of the fours sessions, which were offered twice in the same day to each group. Topics for each session were: (1) Overview (which addressed smoking but was not advertised as targeting smoking); (2) Cholesterol and weight loss; (3) Exercise and stress; and (4) Return to work following a heart attack. In each session, the speaker defined the importance of particular risk factors in readily understandable terms and conveyed general recommendations for behavior change in each area (e.g., the session covering smoking included how and when to set a quit date). Despite top management's decision that every employee who wanted to attend these sessions should be provided company time to do so, not all nonparticipation was voluntary. Anecdotal reports indicated some employees missed sessions because of travel conflicts and staffing decisions of supervisors.

\section{Operational Definitions of Major Variables}

\section{Recruitment and Participation}

The term recruitment is used to designate the completion of the screening phase of the program. Among those employees recruited, the term participation is used to designate the proportion of the four Weekly Presentations attended. Among employees at risk, targeted participation was used to designate attendance at the session addressing the individual's particular risk factor(s): (1) elevated cholesterol, (2) overweight, (3) stress, and (4) physical inactivity. Other participation was defined as attendance at those sessions which addressed general information (Session 1 and Session 4) and those sessions which were advertised as addressing risk factors the employee did not have. (For example, other participation for nonoverweight employees with low cholesterol would be attendance at Session 2 advertised as Cholesterol and Weight Loss).

\section{Risk Factors}

Employees at risk were those employees whose screening results identified one or more of the following risk factors: (1) smoking-any cigarette smoking within the last week; (2) high blood pressure-either systolic greater than 140 and/or diastolic greater than 90 ; (3) elevated cholesterol-serum cholesterol greater than 200 if age greater than 30 , or greater than 180 if age less than or 
equal to 30 ; (4) overweight - greater than $20 \%$ over ideal body weight; (5) Type A response to stress ${ }^{11}$ - greater than 75 th percentile on the short form of the Jenkins Activity Survey; ${ }^{*}$ and (6) physical inactivity-seven-day recall of physical activity in lower third of population. ${ }^{14}$ Lastly, each employee received the American Heart Association's Framingham-based composite score of cardiovascular risk, RISKO.

\section{Organizational Climate}

To assess employee's perceptions of various dimensions of organizational function at the worksite, the Organizational Climate Survey was administered. ${ }^{15}$ For the purpose of this study, 14 health-related items were added. The following subscales emerged utilizing factor analyses with a promax (oblique) rotation allowing correlations among factors. Interitem reliability coefficients are provided for each subscale.

General Climate (13 items)

Worktime Flexibility for Personal Needs (3 items) $\quad .74$

General Support for Health Promotion (4 items) $\quad .70$

Management Support for Health Promotion (3 items) $\quad .76$

Co-Worker Support for Health Promotion (4 items) $\quad .88$

\section{Intent to Improve}

Employees were asked to indicate their intent (yes/no) to make a serious effort in the next six months to improve their health habits in the areas of smoking, weight, stress, physical fitness, and nutrition. Because all employees could improve in the last three areas, their responses regarding stress, physical fitness, and nutrition were summed as a composite measure of intent to improve. In addition, intent to quit smoking was examined for smokers. Intent to lose weight was examined only for those individuals who were $10 \%$ or more above their ideal body weight.

\section{RESULTS}

Sixty-four percent of employees $(n=679)$ were recruited to the program with rates ranging from $42 \%$ to $100 \%$ in all 13 divisions. In the two divisions selected for the recruitment analysis, $58.4 \%$ of employees were recruited. Sociodemographic and risk factor characteristics of employees recruited to the program were calculated to describe the population in which we examined predictors of participation. In terms of sociodemographic characteristics, $13.7 \%$ of

\footnotetext{
${ }^{*}$ Constraints inherent in worksite research prohibited the administration of the lengthy structured interview. ${ }^{12}$ While the JAS is clearly less effective in predicting cardiovascular disease than the structured interview, meta-analysis ${ }^{13}$ indicates that JAS-assessed Type A behavior is significantly predictive of cross-sectionally and prospectively determined cardiovascular disease.
} 
employees recruited to the program were over 50 years old, $49.4 \%$ were management, $67.6 \%$ female, $63.7 \%$ married, $23.6 \%$ college graduated and $80.7 \%$ employed in the organization over five years. In terms of risk factors, $27.9 \%$ of employees recruited to the program were cigarette smokers, $7.0 \%$ had high blood presure, $52.7 \%$ had high cholesterol, $33.7 \%$ were greater than $20 \%$ over ideal body weight, $22.7 \%$ were characterized by the JAS as Type A, and $40.1 \%$ reported low levels of exercise.

Eighty-six percent of employees recruited to the program attended at least one of the four sessions. Average attendance rate at the four sessions was $59.7 \%$ $(\mathrm{SD}=34.6)$ with $62 \%$ of subjects participating in the Overview, $62 \%$ in Cholesterol and Weight Loss, $60 \%$ in Exercise and Stress, and 55\% in Return to Work.

\section{Comparison of Sociodemographic Predictors of Recruitment and Participation}

Response rate for the mail questionnaire distributed to a subsample to assess the sociodemographic characteristics of recruited and non-recruited employees was $79.1 \%(55 / 69)$ for the first site and $90.7 \%(39 / 43)$ for the second site. Data for both groups were combined $(N=94)$ to determine predictors of recruitment. Due to the criteria for site selection. employees in Site 1 were significantly more likely to be employed in management positions than employees in Site 2. The two groups did not differ, however. in age. gender, education, or marital status.

Five dichotomized sociodemographic variables were examined by chi-square analysis to assess their relationship to recruitment: age, gender, marital status, education and position within the company (Table 1). Only position within the company was found to be significantly related, with recruited employees more likely to hold management than nonmanagement positions within the company.

Table 1. Sociodemographic Predictors of Recruitment and Participation

\begin{tabular}{clc}
$\begin{array}{c}\text { Recruitment Rate } \\
\text { by Sociodemographic } \\
\text { Subgroup }(\%)\end{array}$ & \multicolumn{1}{c}{$\begin{array}{c}\text { Sociodemographic } \\
\text { Characteristics }\end{array}$} & $\begin{array}{r}\text { Participation Rate } \\
\text { by Sociodemographic } \\
\text { Subgroup (\%) }\end{array}$ \\
\hline 61.0 & 50 years old or less & 60.5 \\
46.7 & Over 50 years old & 63.6 \\
54.7 & Female & 65.0 \\
66.6 & Male & $51.9^{\mathrm{c}}$ \\
53.3 & Less than college graduate & 62.8 \\
73.7 & College graduate & $54.9^{4}$ \\
74.5 & Management & 54.2 \\
$37.2^{\mathrm{b}}$ & Nonmanagement & $67.6^{\mathrm{a}}$ \\
62.5 & Married & 57.8 \\
52.6 & Nonmarried & $66.4^{\mathrm{a}}$ \\
$n=94$ & & $n=679$ \\
\hline
\end{tabular}

" $p<.01$.

${ }^{\mathrm{b}} p<.001$.

${ }^{\mathrm{c}} p<.0001$. 
Trends emerged for recruitment rates to be higher among employees who were over 50 , male, college educated, and married, but these relationships were not significant probably due to the small sample size.

T-tests were used to assess the relationship between the five dichotomized sociodemographic variables and the dependent variable, participation, for all employees recruited to the program. Participation was higher among employees who were female, unmarried, nonmanagement and not college graduates. No significant relationships between age and participation rate were discovered.

\section{Participation by Employees at Risk in Appropriately Targeted Sessions}

To determine whether higher risk employees participated in sessions specifically promoted as addressing their own risk factor(s), (overweight, cholesterol, Type A behavior pattern, and low level of exercise), the attendance of recruited employees at higher risk on each of these four risk factors was compared to the attendance of recruited employees at lower risk. Chi-square analysis indicated that higher risk employees did not attend the specific session targeted to their risk factor(s) at significantly greater rates than lower risk employees for any of the four risk factors. In fact, lower risk employees participated significantly more often in the session addressing stress. Fifty-two percent of employees scoring high on the Type A measure of stress attended the specific session targeting stress, compared to $64 \%$ of employees scoring low on the Type A measure $(p<.05)$.

To determine whether employees at higher risk were selectively avoiding sessions targeted to their risk factor(s), the probability of their attendance at targeted sessions was compared to their attendance rates at the other sessions addressing risk factors they did not have. Although no statistical tests are satisfactory for comparisons of dichotomous and continuous variables within subjects, the descriptive data suggest that employees at higher risk did not selectively avoid sessions addressed to their risks. In fact, specific referrals appear to result in slightly greater participation for employees with elevated cholesterol in the targeted session than in other sessions. Sixty-two percent of the employees with elevated cholesterol participated in the session addressing cholesterol. In comparison, the average attendance of this group at sessions addressing risk factors the employee did not have was $57 \%$. Inactive employees also tended to particpate more often in the session that targeted exercise than in other sessions addressing risk factors they did not have. Sixty-five percent of inactive employees participated in the session addressing exercise. In comparison, the average attendance of this group at sessions addressing risk factors the employee did not have was $50 \%$.

\section{Predictors of Participation Rate in Weekly Presentation Series}

For those employees recruited into the program, Table 2 presents bivariate correlations between employees' participation rates in the four weekly presentations and their risk factors. The data demonstrate that participation in the four 
Table 2. Bivariate Correlations Between Extent of Participation and Recruited Employees Risk Factors and Attitudes

\begin{tabular}{lc}
\hline & $\begin{array}{c}\text { Participation } \\
\text { in Four Sessions }\end{array}$ \\
\hline Risk factors & \\
RISKO & $-.17^{\mathrm{t}}$ \\
Smoking & $-.20^{\mathrm{r}}$ \\
High blood pressure & -.06 \\
Elevated cholesterol & $-.12^{\mathrm{d}}$ \\
Overweight & -.05 \\
Type A response to stress & $-.09^{\mathrm{c}}$ \\
Low levels of exercise & .05 \\
Employee attitudes & - \\
Perception of organization & -.06 \\
General climate & $.10^{\mathrm{d}}$ \\
Worktime flexibility for personal needs & .04 \\
General support for health promotion & -.02 \\
Management support for health promotion & -.01 \\
Co-worker support for health promotion & .04 \\
Intent to Improve Health Behaviors & \\
\hline
\end{tabular}

"Higher scores indicate greater risk.

${ }^{b}$ Higher scores indicate more positive perceptions.

' $p<.05$.

d $p<.01$.

${ }^{c} p<.005$.

${ }^{1} p<.0001$.

sessions was greatest among those employees at least risk for cardiovascular disease, as judged by their composite RISKO score. The negative relationship between RISKO and extended participation rate is only slightly diminished $(r=-.14$ ) when the contribution of smoking status to an individual's RISKO score was partialled out. Nonsmokers participated significantly more often, as did those employees with lower levels of cholesterol and Type A behavior.

Table 2 also includes correlations between participation rate and employee attitudes regarding health and perception of their organizational climate. In examining health attitudes, scores on individual intent to improve items or the composite measure were not significant predictors of participation in the four weekly presentations. Of the five dimensions of organizational climate, only one was significantly related to extended participation. Those employees with more worktime flexibility were more likely to participate both in the initial session and throughout the four weekly presentations.

To explore whether the relationship between risk status and participation was evident at the beginning of the program or emerged over time, attendance across the four sessions for employees in the highest and lowest quartile of risk was plotted (Fig. 1). There were no significant differences in the initial attendance rate of higher versus lower risk employees ( $58 \%$ versus $62 \%$ respectively); however, the overall participation rate of higher risk employees was significantly lower $(51 \%$ versus $61 \%, p<.007)$. 

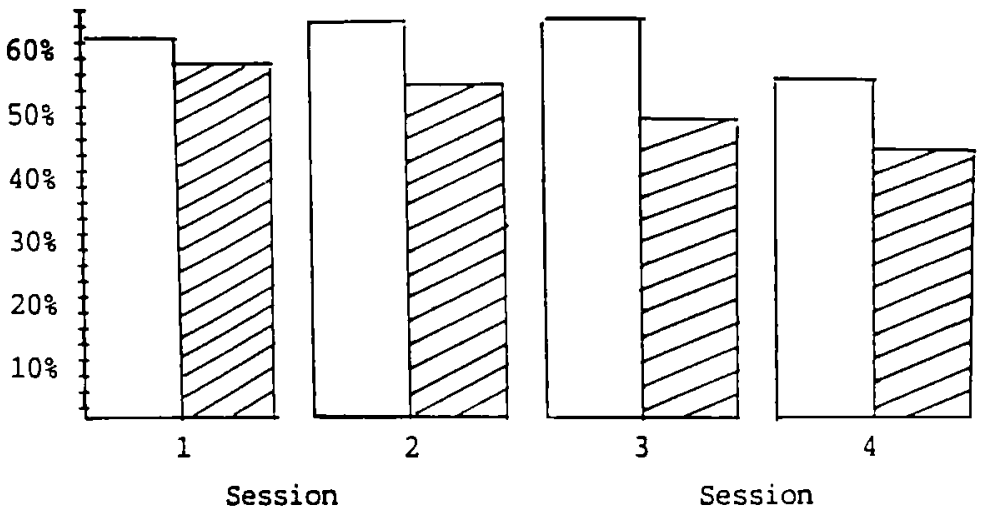

Highest Quartile of Risk ( $n=107)$

Lowest Quartile of Risk ( $n=272$ )

Figure 1. Participation Rate in Four Part Series by Clinical Risk.

Using stepwise linear regression, those sociodemographic, attitudinal and risk factor variables significantly related to participation in bivariate analysis were entered in order of the amount of variance for which they accounted. Sociodemographic variables explain $9 \%$ of the total variance in participation. An additional $7 \%$ of the variance can be attributed to risk factors and less than $1 \%$ to organizational attitudes.

\section{DISCUSSION}

This study examined predictors of recruitment and participation in a comprehensive worksite health promotion program. The findings demonstrated that the predictors of recruitment are almost mirror images of the predictors of participation. Male, management, and highly educated employees were more likely to be recruited, although in all cases the differences were not statistically significant due to small sample size. Among those recruited, female, nonmanagement, and less educated employees were more likely to participate. These findings replicate and extend previous research showing that women participate more extensively over time in community health promotion programs. ${ }^{16}$ The findings also demonstrate that the field would benefit by differentiating employees' initial entry into a health promotion program (which often happens in the context of clinical screening) and their on-going exposure. We have labeled these two phases of involvement, "recruitment" and "participation," respectively.

The mirror-image predictors of recruitment and participation imply that sociodemographic subgroups do not perceive comparable value and/or costs associated with clinical assessment and educational programs. This is perhaps most clearly illustrated in examining why management employees were more likely to be recruited than nonmanagement employees, but less likely to participate 
in on-going programs. Many management employees knew the corporation had previously offered comprehensive cardiovascular assessment only to the top company executives, which most likely promoted managers' willingness to undergo comparable assessments Working Hearts offered in Screening. In contrast, leaders within the nonmanagement community had never been involved in these assessments. Once recruited into the program, the costs of extended participation differed dramatically for the two groups. Management participation in this "company time" program generally translated into demands in addition to their regular work-load. By comparison, participation for nonmanagers generally resulted in reduced job demands.

This analysis highlights that in attempting to understand employee involvement in worksite programs, one needs to consider interactions among social forces influencing behavior and individuals' clinical risks. While several sociodemographic factors were related to recruitment and participation, clinical need is inversely related to extended participation. Total RISKO score. smoking, elevated cholesterol, and Type A score were negatively associated with on-going participation in the four weekly presentations. Employees at greater risk did not appear to selectively avoid the initial session or the special sessions targeting their risk factor(s), yet their attendance rate over four sessions was significantly lower.

Several explanations for this pattern of "preaching to the converted" can be considered. First, high risk individuals not ready to change may have dropped out because of the lifestyle values implicit in the program content. This explanation is consistent with the data which demonstrate no differences in initial attendance between higher and lower risk employees, but differences in ongoing participation. Secondly, some high risk individuals may prefer independent efforts at risk reduction over group programs. This explanation is consistent with previously reported assessments of this same population ${ }^{17}$ in which employees scoring over the 75th percentile on the JAS measure of Type A reported greater independent risk reduction efforts (e.g., dietary change), but were less likely to participate in this group program. Thirdly, if risk status is indicative of a generally risky lifestyle, then one would expect lower participation rates among higher risk employees recruited to the program. The fact that recruited employees at higher risk had comparable participation rates in the first session to recruited employees at lower risk suggests that higher risk employees who go through clinical screening can be initially attracted to educational presentations at the worksite. Even this preliminary exposure may be important because high risk individuals may be unlikely to participate in other community health promotion programs. ${ }^{18.19}$

Epidemiological studies underline the need for worksite programs to assist employees at moderate risk or above. Logarithms suggest that nearly $90 \%$ of all new cases of ischemic heart disease in the next 24 years in this population will develop in $50 \%$ of the subjects who are at higher risk. ${ }^{20}$ We know very little about the extent to which current worksite-wide programs are successful in promoting behavior change in higher risk employees. Although less likely to become extensively involved, higher risk employees may nonetheless be influenced to change by information they receive through their informal social channels and peer models of success. Support for this possibility is evidenced by 
smoking cessation rates of up to $25 \%$ among smokers who did not participate in their worksite smoking program. ${ }^{19}$

If higher risk employees are not benefiting to the degree one would hope, strategies to reach this group need to be carefully considered. One alternative is to design worksite programs specifically for high risk employees, similar to the community-wide programs designed for high risk smokers. ${ }^{21}$ Perhaps the biggest drawback to this approach is the real possibility of provoking illness behavior ${ }^{22}$ in a well population by diagnosing and attempting to "treat" elevated risk factors as one would treat a disease. ${ }^{23} \mathrm{~A}$ more viable strategy may be to develop a high risk emphasis within worksite-wide programs with the objective of sustaining the initial involvement of employees with multiple risk factors. Helpful tactics which practitioners can consider include: (1) expressing a philosophy which overtly acknowledges that employees may be contemplating change, but not yet ready to take action, ${ }^{24.25}$ (2) promoting a variety of attractive resources for behavior change over an extended time, (3) developing and pilot-testing program material with focus groups of high risk employees to minimize dropout due to implicit program messages which communicate expectations discrepant from the high risk employee's personal goals, and (4) skillfully utilizing group process both to influence the meaning the high risk employee attributes to his or her risk factors, and to support their subsequent attempts to change. ${ }^{26}$ This approach has the potential to reach even greater numbers of employees at elevated risk, as well as indirectly influencing them through informal social channels.

The findings of this study underscore the need for health educators in worksite health promotion programs to move beyond traditional referral strategies to involve employees at higher risk for heart disease. Programs emphasizing health promotion activities can introduce the idea of, health promotion to higher risk employees through informal channels (e.g., office salad days and group weight loss contests). Careful monitoring of participation over time may help the health educator gauge the degree to which program is perceived by the overweight smoker as making sense to them, not just as appealing to the low-fat athlete.

The authors acknowledge several limitations of the present study. Regarding recruitment, an unprecedented rate of transfer within the company (annual rate $18 \%$ compared to $5 \%$ in previous years) made a centralized source of accurate personnel records unavailable to study recruitment more extensively. Contract negotiations with the union further limited our ability to survey employees not recruited into the program. The between-site variance in recruitment suggests that innovative research to understand these differences is certainly warranted. Secondly, given that an extensive set of characteristics still explains less than $20 \%$ of the variance in participation in this study and others, ${ }^{9.27}$ further conceptualization of attitudinal and/or social network variables that higher risk employees hold in common is an important priority for understanding factors which inhibit participation.

In summary, recruitment into worksite health promotion needs to be distinguished from extended participation. This study and other studies indicate that both are related to demographic, attitudinal and risk profile variables but in complex and differing ways. Those employees most at risk may be isolated from programs by a variety of social and personal forces resulting in extended par- 
ticipation by those employees at lower risk. Programs targeting higher risk employees nested within worksite-wide efforts may increase involvement by individuals at moderate risk and above, and increase the potential for lower health care costs resulting from employee adoption of healthy lifestyles.

\section{References}

1. Fielding JE: Health promotion and disease prevention at the worksite. Ann Rev Public Health 5:237-265, 1984.

2. Wilbur CS: The Johnson and Johnson Program. Preventive Med 12:672-681, 1983.

3. Leviton LC: The yield from work site cardiovascular risk reduction. $J$ Occupational Med 29:931-936, 1987.

4. Conrad P: Who comes to work-site wellness programs? A preliminary review. $J$ Occupational Med 29:317-320, 1987.

5. Criqui MH, Barrett-Connor E, Austin M: Differences between respondents and nonrespondents in a population-based cardiovascular disease study. Am J Epidemiol 108:367-372, 1978.

6. Settergren SK, Wilbur CS, Hartwell TD, et al: Comparison of respondents and nonrespondents to a worksite health screen. J Occupational Med 25:475-480, 1983.

7. Mirotznik J, Speedling E, Stein R, et al: Cardiovascular fitness program: Factors associated with participation and adherence. Public Health Rep 100:13-18, 1985.

8. Davis KE, Jackson KL, Kronenfeld JJ, et al: Intent to participate in worksite health program activities: A model of risk factors and psychosocial variables. Health Educ Quart 11:361-377, 1984.

9. Sloan RP, Gruman JC. Gruman J: Participation in workplace health promotion programs: The contribution of health and organizational factors. Health Educ Quart 15:269-288, 1988.

10. Zavela KJ, Davis LG, Cottrell RR. Smith WE: Do only the healthy intend to participate in worksite health promotion? Health Educ Quart 15:259-267, 1988.

11. Jenkins CD, Rosenman RH, Friedman M: Development of an objective psychological test for the determination of the coronary-prone behavior pattern in employed men. J Chronic Dis 20:371-379, 1967.

12. Rosenman RH, Swann GE \& Carmelli D: Definition, assessment, and evolution of the Type A behavior pattern, in B.K. Houston \& C.R. Snyder (Eds.): Type A behavior: Research, theory, and intervention ( $p p .8-31$ ), New York, John Wiley \& Sons, 1988.

13. Booth-Kewley S, Friedman HS: Psychological predictors of heart disease: a quantitative review. Psychology Bulletin, 101: 342-362, 1987.

14. Blair SN: How to assess exercise habits and physical fitness, in J.D. Matarazzo (Ed.): Behavioral Health: A Handbook of Health Enhancement and Disease Prevention. New York, John Wiley, 1985.

15. Franklin JL: Down the organization: Influence processes across levels of hierarchy. Admin Science Quart 20:153-164, 1975.

16. Lefebvre RC, Harden E, Rakowski W, Lasater TM, and Carleton RA: Characteristics of participants in community health promotion programs. Am J Public Health 14:13421344, 1987.

17. Rost KM, Watkins PL, Fisher EB, Mickalide AD, Houston CA: Stress and selfinitiated behavioral change. American Public Health Association Meeting, New Orleans, LA, 1987.

18. Fisher EB, Jr., Bishop DB. Mayer J, Brown T, White-Cook T: The physician's contribution to smoking cessation in the workplace. Chest 93: 56S-65S, 1988. 
19. Fisher EB, Jr., Bishop DB, Levitt-Gilmour T, Newman E, Lankester L, Tormey B: Impacts on smoking prevalence of organizational and social support in worksite smoking cessation. Society for Behavioral Medicine, April, 1988.

20. Fraser GE: Implications of the multifactorial etiology of ischemic heart disease for clinical practice, in Preventive Cardiology. New York, Oxford University Press, 1986.

21. Commit Protocol Summary: Community Intervention Trial for Smoking Cessation. National Cancer Institute, Bethesda, MD.

22. Sackett DL, Haynes RB, Gibson ES, et al.: Randomized clinical trial of strategies for improving medication compliance in primary hypertension. Lancet 1:1205-1207, 1975.

23. Safer MA: A comparison of screening for disease detection and screening for risk factors. Health Educ Res: Theory and Practice, 1:131-138, 1986.

24. Prochaska JO, DiClemente CC: Stages and processes of self-change. J Consult Clin Psychol 51:390-395, 1983.

25. Abrams DB, Elder JP, Carleton RA, Lasater TM, Artz LM. Social learning principles for organizational health promotion: An integrated approach. In M.F. Cataldo \& T.J. Coates (Eds.); Health and Industry A Behavioral Medicine Perspective. New York, Wiley-Interscience, 1986.

26. Levin K: "Group decision and social change," in TM Newcomb and EL Hartley (Eds.): Readings in Social Psychology, New York, Holt, Rinehart and Winston, 1947.

27. Davis KE, Jackson KL, Kronenfeld JJ, et al: Determinants of participation in worksite health promotion activities. Health Educ Quart 14:195-205, 1987. 